\title{
Intrauterine degeneration of embryos in IUD-bearing mice
}

\author{
P. R. Hurst, Kathryn Jefferies, P. Eckstein and A. G. Wheeler \\ Department of Anatomy, Medical School, University of Birmingham, Birmingham B15 2TJ, U.K.
}

The mouse uterus reacts to a unilateral intrauterine device (IUD) by developing partial-to-complete sterility in both the IUD- and contralateral horn (Doyle \& Margolis, 1966; Marston \& Kelly, 1969; Martin \& Finn, 1970). Fertilization, tubal transport and development of embryos appear to be unaffected in such animals, but the numbers of embryos that can be recovered by flushing the uterus at the time at which they can be expected to have entered the horns are smaller than those recoverable from controls (Marston \& Kelly, 1969; and our unpublished data). Flushing therefore does not distinguish between intrauterine death or premature expulsion of embryos from the mouse uterus. In an attempt to discover the fate of embryos in IUD-bearing mice the following histological experiment was undertaken.

\section{Methods and results}

The 6-8-week-old mice were of the LACA strain. Suture IUDs of braided silk (6/0 gauge) were inserted into the middle third of randomly-selected single horns at laparotomy. Control animals were sham-operated by passing a needle and silk through one horn. Following a rest period of 3 weeks females were mated during the final hour $(09.00-10.00 \mathrm{~h})$ of the 14-h dark period.

Six IUD-bearing mice were killed at $72 \mathrm{~h}$ p.c., 6 at $96 \mathrm{~h}$ and a further 3 at $120 \mathrm{~h}$. At autopsy, corpora lutea $(\mathrm{CL})$ in both ovaries were counted under a dissecting microscope and the entire reproductive tract above the cervix was fixed in Bouin's fluid. Serial, longitudinal sections $(7 \mu \mathrm{m})$ of the horns and oviducts were prepared and stained with haematoxylin and periodic acid-Schiff reagent. At least 300 sections per complete reproductive tract were examined for the presence and location of embryos.

The results are summarized in Table 1. In the sham-operated controls examined at 72 and $96 \mathrm{~h}$ p.c., blastocysts were seen spaced along both uterine horns, and no polymorphonuclear leucocytes (PMNLs) were observed in the lumina of either the horns or the oviducts. In one animal killed at $96 \mathrm{~h}$ p.c. ovum attachment had occurred, and there was evidence of normal decidual cell development in the underlying stroma.

In all IUD-bearing animals large masses of PMNLs were seen to surround the IUD and to extend from it towards both the ovarian and cervical extremities of the horn, frequently filling the lumen (Pl. 1, Fig. 1). In two mice examined at $72 \mathrm{~h}$ p.c., 9 embryos were detected, all of them in the oviducts on the IUD side. In one of these animals 4 degenerated embryos were present (Pl. 1, Fig. 2), and in the other 5 apparently normal blastocysts were clustered in the isthmus. Small numbers of PMNLs were observed at the periphery of four of these embryos. In the other 4 animals examined at $72 \mathrm{~h}$ p.c. 18 embryos were detected in the horns, lying between the IUD and uterotubal junction, all being surrounded by PMNLs. These embryos lacked zonae pellucidae, probably due to their dissolution by the Bouin fixative. Mitotic figures were seen in several embryos. but 10 of 18 had hypertrophied and irregularly shaped cells, and appeared to be degenerating (Pl. 1, Fig. 3). The numbers of embryos in the contralateral horn at $72 \mathrm{~h}$ p.c. in relation to $\mathrm{CL}$ agreed well with those in controls (Table 1). The embryos were normally spaced in 5 of the 6 horns; in the other horn 4 embryos were bunched together in the middle region. Every embryo observed at $72 \mathrm{~h}$ p.c. was surrounded by localized clusters of PMNLs (Pl. 2, Fig. 4). Some embryos were considered to be degenerating, and in two horns PMNLs were observed between individual blastomeres (PI. 2, Fig. 5). Fewer PMNLs were found in the lumen, epithelium and stroma of the contralateral horns compared with those on the IUD side (P1. 2, Fig. 6).

Two of the 6 IUD-bearing mice killed at $96 \mathrm{~h}$ p.c. had no embryos in either the uterus or oviduct, but all contained masses of PMNLs in the horns on the IUD side. Degenerated embryos were present 
Table 1. The numbers of embryos and corpora lutea (CL) observed in the oviducts and uteri of mice bearing a unilateral intrauterine device (IUD)

\begin{tabular}{|c|c|c|c|c|c|}
\hline & \multicolumn{2}{|c|}{ Controls* } & \multicolumn{3}{|c|}{ With IUDs } \\
\hline & 72 & 96 & 72 & 96 & 120 \\
\hline No. of mice & 3 & 4 & 6 & 6 & 3 \\
\hline $\begin{array}{l}\text { Oviductal embryos } \\
\text { Operated side } \\
\text { Unoperated side }\end{array}$ & $\begin{array}{l}0 \\
0\end{array}$ & $\begin{array}{l}0 \\
0\end{array}$ & $\begin{array}{l}9(2) \\
0\end{array}$ & $\begin{array}{l}5(1) \\
0\end{array}$ & $\begin{array}{l}0 \\
0\end{array}$ \\
\hline $\begin{array}{l}\text { Uterine embryos } \\
\text { Operated side } \\
\text { Unoperated side }\end{array}$ & $\begin{array}{l}14(3) \\
17(3)\end{array}$ & $\begin{array}{l}20(4) \\
18(4)\end{array}$ & $\begin{array}{l}18(4) \\
31(6)\end{array}$ & $\begin{array}{l}11(3) \\
22(6)\end{array}$ & $\begin{array}{l}6(2) \\
7(2)\end{array}$ \\
\hline $\begin{array}{l}\text { CL } \\
\quad \text { Operated side } \\
\text { Unoperated side }\end{array}$ & $\begin{array}{l}17 \\
19\end{array}$ & $\begin{array}{l}26 \\
25\end{array}$ & $\begin{array}{l}40 \\
37\end{array}$ & $\begin{array}{l}36 \\
34\end{array}$ & $\begin{array}{l}21 \\
18\end{array}$ \\
\hline $\begin{array}{c}\text { Total embryos obse } \\
\text { CL }(\%) \\
\text { Operated side } \\
\text { Unoperated side }\end{array}$ & $\begin{array}{l}82 \cdot 3 \\
89 \cdot 4\end{array}$ & $\begin{array}{l}76.9 \\
72.0\end{array}$ & $\begin{array}{l}67.5 \\
83.7\end{array}$ & $\begin{array}{l}44 \cdot 4 \\
64 \cdot 7\end{array}$ & $\begin{array}{l}28 \cdot 5 \\
38 \cdot 8\end{array}$ \\
\hline
\end{tabular}

The number of mice yielding embryos is given in parentheses.

* Sham-operated.

in the oviduct next to the IUD horn of one female. Three other mice contained PMNL-surrounded embryos showing a more advanced degree of degeneration than observed at $72 \mathrm{~h}$ p.c. One contralateral horn contained 5 blastocysts free of PMNLs and in the initial stages of attachment; the endometrium showed normal decidual cell development. Only a few stromal leucocytes were present in this specimen, and its histological appearance was similar to that of controls. In the remaining horns, degenerated unattached embryos surrounded by PMNLs were present, and there was no development of the decidual cell reaction.

In one animal at $120 \mathrm{~h}$ p.c. no embryos were detected in either horn. In the other two mice, degenerated embryos were seen in both the IUD-containing and contralateral horns. In the former only fragmented embryonic cellular material was found (Pl. 2, Fig. 7), one mass of which showed an intercellular accumulation of PMNLs.

\section{Discussion}

Our findings show that mouse embryos in IUD-containing tracts can be detected by serial sectioning at 72 and $96 \mathrm{~h}$ p.c. The embryos are present either in the oviducts ('tube-locked') or in the cranial portions of the uterine horns surrounded by PMNLs. In normal females of the strain of mouse used by us embryos enter the uterus at about $66 \mathrm{~h}$ p.c. (Mackay, 1972). Since there was no evidence of PMNLs in the lining epithelium or the stroma of the oviducts of IUD-fitted mice, the PMNLs associated with tube-locked embryos presumably originated in the uterus and thence entered the tubal lumen. This probably occurred in direct response to the presence of embryos because no intratubal PMNLs were observed in other oviducts not containing embryos.

The presence of PMNLs around the embryos and the progressive signs of embryonic degeneration in the uteri of IUD-bearing mice from 72 to $120 \mathrm{~h} \mathrm{p.c.} \mathrm{suggests} \mathrm{that} \mathrm{such} \mathrm{embryos} \mathrm{undergo}$ arrest of development and subsequent degeneration. Nevertheless, the lower embryo-to-CL ratio present in such horns compared with sham-operated control horns (Table 1) could indicate that the unidentified proportion of embryos was prematurely expelled through the cervix. However, the conspicuous mass of PMNLs which usually occludes most of the lumen of IUD-containing horns can be expected to act as an effective barrier to the passage of embryos from oviduct to vagina. Also, when present in tracts with IUDs, uterine embryos were always located in the cranial segment of the 
PLATE 1
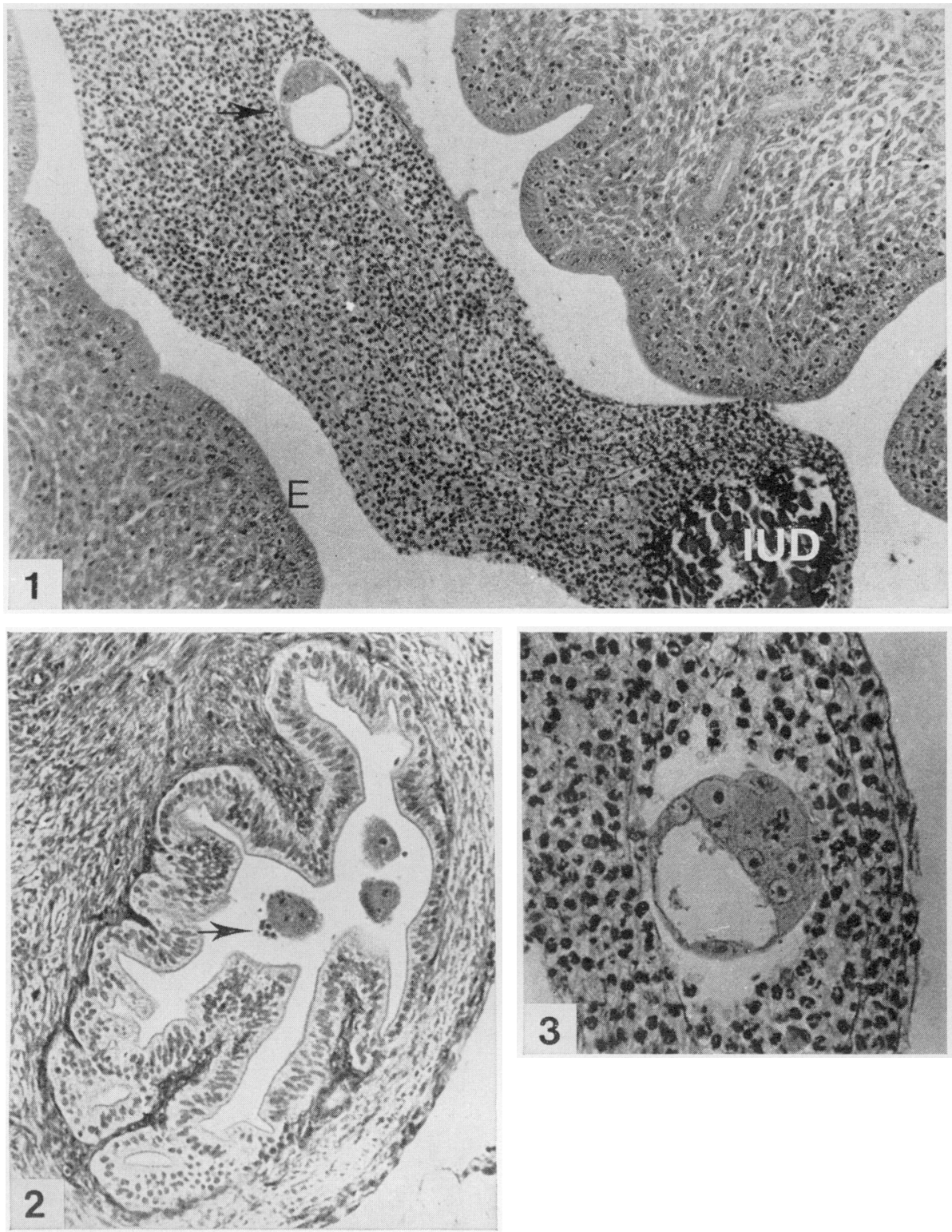

Fig. 1. IUD-containing horn $72 \mathrm{~h}$ p.c. Mass of PMNLs surrounding IUD and one blastocyst (arrowed). PMNLs also present in uterine stroma and epithelium (E). $\times 180$

Fig. 2. Oviduct on IUD side $72 \mathrm{~h}$ p.c. Three degenerating embryos with a few associated PMNLs (arrowed). $\times 180$.

Fig. 3. IUD-containing horn $72 \mathrm{~h}$ p.c. Blastocyst with hypertrophied cells containing nitotic figures and condensed chromatin. $\times 460$. 

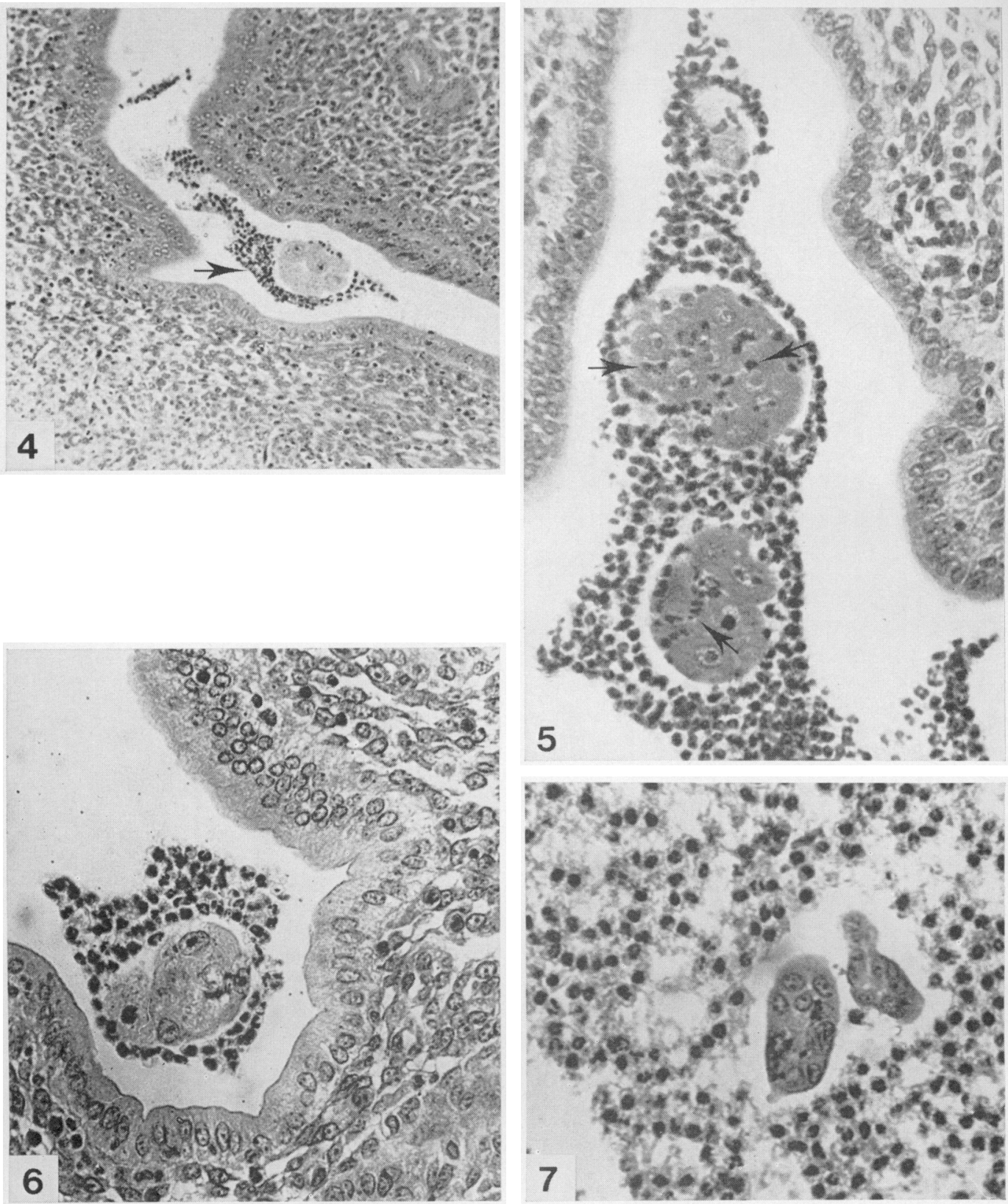

Fig. 4. Contralateral horn $72 \mathrm{~h}$ p.c. Degenerating embryo surrounded by PMNLs (arrowed). PMNLs also present in uterine stroma and epithelium. $\times 180$.

Fig. 5. Contralateral horn 72 h p.c. Cluster of embryos with numerous intercellular PMNLs (arrowed). $\times 460$.

Fig. 6. Contralateral horn $72 \mathrm{~h}$ p.c. Degenerating embryo surrounded by PMNLs. Note reduced number of PMNLs in stroma and epithelium. $\times 460$.

Fig. 7. IUD-containing horn $120 \mathrm{~h}$ p.c. Degenerated embryonic masses surrounded by PMNLs. $\times 460$. 
horn, between the IUD and uterotubal junction. It is probable that in some uteri degeneration of embryos was exceptionally rapid, causing their obliteration and preventing identification by the time of fixation. On the contralateral side there was no evidence of tube-locking, and in all except one mouse uterine embryos were found to be associated with PMNLs. A number of these embryos were seen to be degenerating, as on the IUD side. In two contralateral horns PMNLs were observed between blastomeres, but since this was not seen in the remaining uteri the relationship between PMNLs and embryonic degeneration remains to be elucidated. One possibility is that PMNLs invade or phagocytose embryos. Alternatively, they may, by directly surrounding the embryos (see Pl.1, Fig.1), form a barrier which interferes with the passage of essential nutrients from thelumen, and so makes autolysis of embryos inevitable.

In the majority of species studies so far an IUD induces a cellular (PMNL or macrophage) invasion of the uterine lumen, and this feature appears to be an important aspect of intrauterine contraception (see Greenwald, 1965; Parr, Schaedler \& Hirsch, 1967; El Sahwi \& Moyer, 1971; Cuadros \& Hirsch, 1972; Bo, Krueger \& Bartley, 1974; Myatt, Bray, Gordon \& Morley, 1975). The present observations strongly support the view that in the mouse a silk IUD exerts its antifertility action principally by leucocyte-mediated degeneration of uterine embryos, and partly by retention of embryos in the oviduct.

We thank Mrs Janet Parker for her help with the illustrations and Mrs Gladys Macbeth for secretarial assistance. The support of the Ford Foundation (Grant no. 639-0576B) is gratefully acknowledged.

\section{References}

Bo, W.J., Krugger, W.A. \& Bartley, C.M. (1974) The influence of chlorambucil on IUD-induced uterine neutrophils. Contraception 10, 667-672.

Cuadros, A. \& Hirsch, J.G. (1972) Copper on intrauterine devices stimulates leukocyte exudation. Science, N.Y. 175, 175-176.

Doyle, L.L. \& Margolis, A.J. (1966) The effect of an IUFB on reproduction in mice. $J$. Reprod. Fert. 11, 27-32.

El SAHWI, S. \& MoYer, D.L. (1971) The leukocytic response to an intrauterine foreign body in the rabbit. Fert. Steril. 22, 398-408.

Greenwald, G.S. (1965) Interruption of pregnancy in the rat by a uterine suture. $J$. Reprod. Fert. 9, 9-17.

Marston, J.H. \& Kelly, W.A. (1969) The time and site of contraceptive action of an intra-uterine device in the mouse. J. Endocr. 43, 83-93.

MARTIN, L. \& FINN, C.A. (1970) The effects of an intrauterine device on uterine cell division and epithelial morphology during early pregnancy in the mouse. J. Endocr. 48, 347-354.

MACKAY, S. (1972) Contraceptive effects of the intrauterine device in the mouse. B.Sc. thesis, University of Birmingham.

MyatT, L., Bray, M.A., Gordon, D. \& Morley, J. (1975) Macrophages on intrauterine contraceptive devices produce prostaglandins. Nature, Lond. 257, 227-228.

PARR, E.L., Schaedler, R.W. \& Hirsch, J.G. (1967) The relationship of polymorphonuclear leucocytes to infertility in uteri containing foreign bodies. $J$. exp. Med. 126, 523-538.

Received 23 December 1976 